\title{
Is Endoscopic Transurethral Incision Really Effective for Boys with Refractory Daytime Incontinence?
}

This article was published in the following Dove Press journal:

Research and Reports in Urology

\section{Yosuke Morizawa $\mathbb{D}$ \\ Katsuya Aoki \\ Shunta Hori (iD \\ Daisuke Gotoh (1C) \\ Makito Miyake (D) \\ Yasushi Nakai (D) \\ Kazumasa Torimoto (iD \\ Nobumichi Tanaka (D) \\ Kiyohide Fujimoto}

Department of Urology, Nara Medical University, Kashihara, Nara, Japan
Correspondence: Kiyohide Fujimoto Department of Urology, Nara Medical University, 840 Shijo-cho, Kashihara, Nara 634-8522, Japan

Tel +8I-744-22-305I

Fax +81-744-22-9282

Email kiyokun@naramed-u.ac.jp
Purpose: To determine the clinical efficacy of endoscopic transurethral incision (TUI) for boys with refractory daytime incontinence due to a posterior urethral valve with or without nocturnal enuresis.

Patients and Methods: A total of 20 boys with daytime incontinence were assessed. Twelve boys underwent TUI (TUI+ group) and eight boys continued receiving oral drugs (TUI- group). The primary endpoint was the cure rate associated with TUI or NE in both groups.

Results: Only two boys achieved daytime continence 6 months after TUI, but no boys were cured of nocturnal enuresis 6 months after TUI. The median time to daytime continence was significantly longer in the TUI+ than in the TUI- group (52 vs 27 months, respectively; log rank $\mathrm{P}=0.041)$ and the median time to dry nights was significantly longer in the TUI+ than in the TUI- group (56 vs 36 months, respectively; $\log$ rank $\mathrm{P}=0.021$ ).

Conclusion: TUI might be not effective in boys with refractory daytime incontinence.

Keywords: pediatric, daytime incontinence, enuresis, TUI

\section{Introduction}

Up to $90 \%$ of children with daytime urinary incontinence (DUI) achieve daytime continence through standard urotherapy and anticholinergics. ${ }^{1}$ Nevertheless, the treatment for some children is complex. According to the International Children's Continence Society (ICCS), refractory children after standard treatment for DUI require invasive examinations for anatomical genitourinary tract anomalies. ${ }^{2}$ Voiding cystourethrography (VCUG) is useful for children with refractory DUI and can reveal bladder deformities, such as diverticula, vesicoureteral reflux, dilated posterior urethra, or posterior urethral valves (PUV). ${ }^{2}$ Most typical abnormal finding in boys with DUI by VCUG is mild urethral obstruction by PUV. Transurethral incision (TUI) is usually indicated for boys with PUV. Several studies reported that TUI could improve clinical urinary symptoms in boys with PUV with delayed presentation. ${ }^{3-5}$ However, the clinical significance for delayed presentation of PUV with refractory lower urinary tract symptoms, such as DUI or nocturnal enuresis (NE), remains unknown. Therefore, we evaluated the clinical efficacy of TUI for boys with refractory DUI.

\section{Patients and Methods Patients and Data Collection}

This study was approved by the Medical Ethics Committee of Nara Medical University (NMU-2042) and complied with the 1964 Declaration of Helsinki and 
its later amendments or with comparable ethical standards. Informed consent was obtained from all patients and all parents.

Between 2006 and 2013, a total of 73 boys with DUI were enrolled in the study. VCUG and urodynamic studies were performed in 35 boys who had refractory symptoms after conservative treatment, including urotherapy and anticholinergic drugs, such as oxybutynin, propiverine and solifenacin, for at least 1 year. Among the 35 boys, 20 who had suspected urethral obstructions in the posterior urethra by VCUG were enrolled (Figures 1 and 2). Two urologists (YM and KA) assessed all the VCUG. Of these 20 boys, 18 (90\%) had NE. All patients were recommended for PUV diagnosis confirmation by urethrocystoscopy and for TUI when needed. Of the 20 boys, 12 (TUI+ group) underwent urethrocystoscopy and TUI under general anesthesia. Eight boys (TUI- group) decided to continue oral drug administration without undergoing urethrocystoscopy. An 8.5-Fr endoscope (Richard Wolf GmbH, Knittlingen, Germany) was carefully used to observe PUV, even with minor urethral lesions. After filling the bladder with saline, the suprapubic area was compressed and impressed to completely dilate the posterior urethra. TUI was performed under the same anesthesia using a sickle-type cold knife. A sufficient incision was made in the membranous lesion, extending down from the anterior urethral wall at $12 \mathrm{o}$ 'clock. Additional incisions were

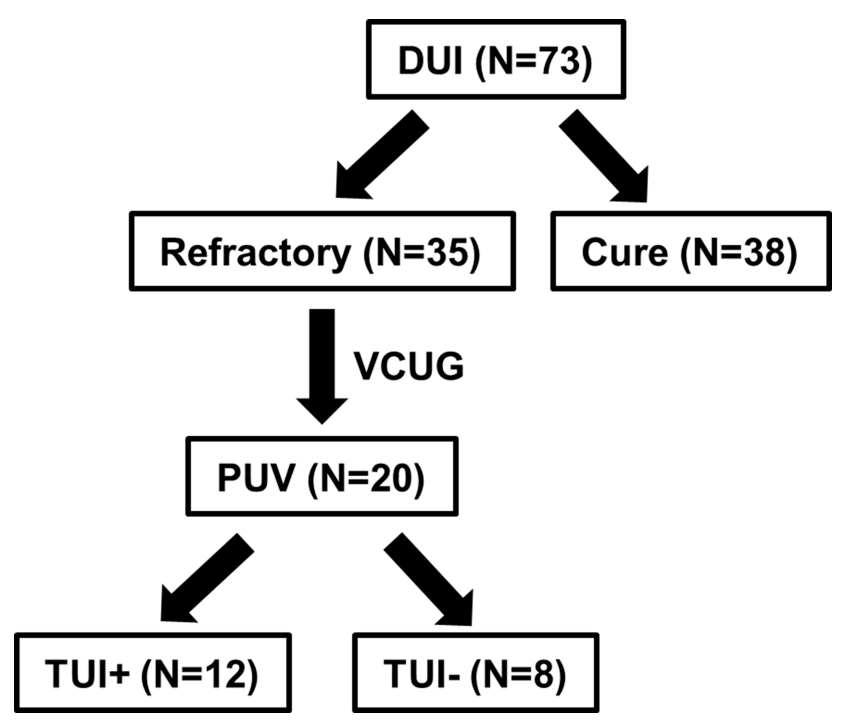

Figure I A total of 73 boys with DUI were diagnosed and VCUG and urodynamic studies were performed in 35 boys who were refractory to conservative treatment. Among the 35 boys, 20 had suspected urethral obstruction in the posterior urethra by VCUG. Of the 20 boys, 12 (TUI+ group) underwent urethrocystoscopy and TUI under general anesthesia and 8 (TUl- group) continued receiving oral drugs without urethrocystoscopy.

Abbreviations: DUI, daytime urinary incontinence; PUV, posterior urethral valves; TUI, transurethral incision; VCUG, Voiding cystourethrography.

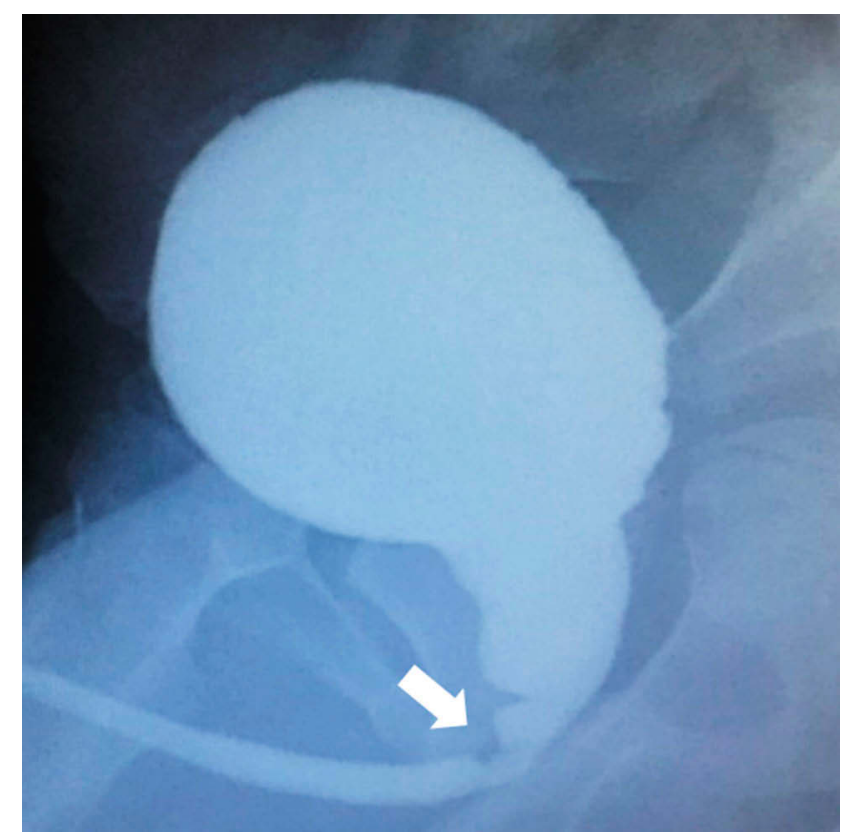

Figure 2 Radiological appearance of posterior urethral valve on voiding cystourethrography.

made in the valve structure at 5 or 7 o'clock, where needed. The primary endpoint was the cure rate for DUI or NE in the TUI+ and TUI- groups. The outcome was defined as a complete cure or when DUI or NE had disappeared completely. Response rates at 6 months after TUI were evaluated. The response was defined according to the ICCS standardization guidelines as follows: complete, partial, and no response as a $100 \%, 50-99 \%$, and $0-49 \%$ decrease in the number of instances of DUI or wet nights, respectively.

All children were evaluated using the mean age, a dysfunctional voiding symptom score (DVSS), the presence of constipation, maximum urinary flow rate (Qmax), average urinary flow rate, the measurement of residual urine, detrusor pressure at Qmax, bladder compliance, a dyssynergic pattern in urodynamic study, ${ }^{7}$ flexion rate, and follow-up period. The minimum urethral angle and flexion rate were defined as the angle formed by VCUG during urination. ${ }^{6}$ The maximum voided volume (MVV) was recorded in a bladder diary, and the expected bladder capacity $(\mathrm{EBC})$ was calculated using the following formula: $[30+($ age in years $\times 30)](\mathrm{mL})$. The boys in the TUI + group were evaluated at 3-6 months later after TUI by VCUG, bladder diary, and uroflowmetry parameters.

\section{Statistical Analysis}

Clinical characteristics were compared using the MannWhitney $U$-test, chi-squared test, and analysis of variance. The cutoff date of the last follow-up was December 31, 
2017. The percentages of boys becoming dry over time or having dry nights were examined using the Kaplan-Meier method. GraphPad Prism software (version 7.03, GraphPad Software; San Diego, CA) was used for statistical analyses and data plotting. P-values $<0.05$ were defined as statistically significant.

\section{Results}

The clinical characteristics of the patients are shown in Table 1. The mean ages in the TUI- and TUI+ groups were 7.0 (range: 5-12) and 6.4 (range: 5-10) years, respectively. There were no significant differences in the baseline urinary frequency, average voiding volume, MVV, MVV/EBC, constipation, Qmax, average urinary flow rate, void residual volume, detrusor pressure at Qmax, minimum urethral angle, or flexion rate between the TUI- and TUI+ groups. Eleven (92\%) and four (33\%) patients had COPUM and Cobb's collar type obstruction, respectively. ${ }^{15,16}$ Three boys (25\%) had both COPUM and Cobb's collar types. Four and eight boys in the TUI+ group had a synergic and a dyssynergic pattern, respectively. In the TUI+ group, abnormal findings of urethral obstruction in the posterior urethra before TUI improved according to VCUG at 3-6 months after TUI. There were no significant differences in the urinary frequency, average voiding volume, MVV, MVV/EBC, Qmax, average urinary flow rate, and void residual volume between before and after TUI (Table 2). In the TUI+ group, three boys showed complete or partial response at 6 months after TUI, but nine boys showed non-response for DUI. No boy showed complete or partial response for NE at 6 months after TUI. All the boys in the TUI+ group continued urotherapy and anticholinergic drug administration, and the drugs were gradually reduced when DUI completely decreased. Most boys needed continued oral medication after TUI. Imipramine was added to urotherapy and anticholinergic drug administration for some boys in the TUI- and TUI+ groups. All boys in the TUI- group had cured DUI or NE (median, 27 and 36 months, respectively; Figure $3 \mathrm{~A}$ and $\mathrm{B})$. Ten (83\%) and nine boys $(75 \%)$ in the TUI+ group were cured of DUI and $\mathrm{NE}$ in the follow-up period, respectively (median, 52 and 56 months, respectively; Figure $3 \mathrm{~A}$ and $\mathrm{B}$ ). There were no obvious adverse events, such as bleeding or urethral stenosis, due to TUI in the follow-up period.

\section{Discussion}

Previous studies suggested that boys treated for PUV had improved urinary symptoms of DUI and NE. ${ }^{3-11}$ However, in the present study, only two boys (17\%) achieved daytime continence at 6 months after TUI and no boy was cured of NE at 6 months after TUI. Nakamura divided boys with PUV into two groups before TUI: those with a synergic pattern on urodynamics with a quiet electromyogram during filling and those with a dyssynergic pattern with increased electromyogram activity as the bladder filled. ${ }^{7}$ DUI improved in seven

Table I Patients' Characteristics

\begin{tabular}{|c|c|c|c|c|}
\hline & All $(\mathrm{N}=\mathbf{2 0})$ & TUI- $(\mathbf{N}=8)$ & TUI+ $(\mathrm{N}=12)$ & $P$ value \\
\hline Age, year (Range) & $6.7(5-12)$ & $7(5-12)$ & $6.4(5-10)$ & 0.61 \\
\hline DVSS (Range) & $9(4-17)$ & $7(4-11)$ & $10(5-17)$ & 0.24 \\
\hline Frequency (Range) & $10(6-16)$ & $9(6-13)$ & $10(7-16)$ & 0.58 \\
\hline AVV, mL (Range) & $74(40-110)$ & $74(50-100)$ & $75(40-110)$ & 0.91 \\
\hline MVV, mL (Range) & $137(60-250)$ & $128(70-180)$ & $144(80-250)$ & 0.85 \\
\hline MVV/EBC, \% (Range) & $59(33-119)$ & 50 (33-89) & $60(33-119)$ & 0.44 \\
\hline Constipation, n (\%) & $4(20)$ & $2(25)$ & $2(17)$ & 0.64 \\
\hline Qmax, mL/s (Range) & $18.9(6.2-44.8)$ & $22.3(6.2-44.2)$ & $17.3(6.3-44.8)$ & 0.73 \\
\hline Average flow rate, $\mathrm{mL} / \mathrm{s}$ (Range) & $7.8(3.2-11.2)$ & $8.2(4.8-10.2)$ & $7.6(3.2-11.2)$ & 0.69 \\
\hline PVR, mL (Range) & $7.9(0-11.5)$ & $10.9(0-40)$ & $6.4(0-31)$ & 0.62 \\
\hline Enuresis, n (\%) & $18(90)$ & $7(88)$ & II (92) & 0.76 \\
\hline Pdet at Qmax, $\mathrm{cmH}_{2} \mathrm{O}$ (Range) & $130(100-177)$ & $132(102-177)$ & $120(100-144)$ & 0.49 \\
\hline Compliance, $\mathrm{mL} / \mathrm{cmH}_{2} \mathrm{O}$ (Range) & $12.9(0.7-20)$ & $14.2(8.6-20)$ & $12.4(0.7-30)$ & 0.50 \\
\hline Dyssynergic pattern, n (\%) & $13(65)$ & $5(63)$ & $8(67)$ & 0.61 \\
\hline Minimum urethral angle, ${ }^{\circ}$ (Range) & $107.4(84-136)$ & $106.1(95-120)$ & $108.2(84-136)$ & 0.93 \\
\hline Flexion rate, \% (Range) & $9.3(1.6-27.4)$ & $8.1(1.6-20.9)$ & $9.9(2.0-27.4)$ & 0.56 \\
\hline Follow-up, months (Range) & $51(18-112)$ & $38.5(18-65)$ & $59(29-112)$ & 0.059 \\
\hline
\end{tabular}

Abbreviations: AVV, average voiding volume; DVSS, dysfunctional voiding scoring system; EBC, expected bladder capacity; MVV, maximum voided volume; Pdet at Qmax, detrusor pressure at the maximum flow rate; PVR, void residual volume; Qmax, maximum urinary flow rate. 
Table 2 Change of Bladder Diary and Uroflowmetry Parameters Before and After TUI

\begin{tabular}{|l|l|l|l|}
\hline & Before TUI & After TUI & P value \\
\hline Frequency (Range) & $10(7-16)$ & $10(8-12)$ & 0.91 \\
AVV, $\mathrm{mL}$ (Range) & $75(40-110)$ & $91(50-123)$ & 0.86 \\
$\mathrm{MVV}, \mathrm{mL}$ (Range) & $144(80-250)$ & $146(90-300)$ & 0.97 \\
$\mathrm{MVV/EBC,} \mathrm{\%} \mathrm{(Range)}$ & $60(33-119)$ & $66(30-167)$ & 0.88 \\
Qmax, mL/s (Range) & $17.3(6.3-44.8)$ & $18.4(13.4-30.8)$ & 0.49 \\
Average flow rate, $\mathrm{mL} / \mathrm{s}$ (Range) & $7.6(3.2-11.2)$ & $7.9(4.6-11.3)$ & 0.88 \\
PVR, $\mathrm{mL}$ (Range) & $6.4(0-31)$ & $1.3(0-3.8)$ & 0.36 \\
\hline
\end{tabular}

Abbreviations: AVV, average voiding volume; EBC, expected bladder capacity; MVV, maximum voided volume; PVR, void residual volume; Qmax, maximum urinary flow rate.

of the eight boys with synergic patterns, but no boy with a dyssynergic pattern had improvement. ${ }^{7}$ In the present study, four (33\%) and eight (67\%) boys in the TUI+ group had a synergic and a dyssynergic pattern, respectively. AVV, MVV, Qmax, and PVR did not change before and after TUI, but frequency decreased from 11 to five in the boys with synergic patterns. After 6 months of treatment, TUI was effective for only three boys with a synergic pattern and was not effective for eight boys with a dyssynergic pattern. The efficacy of TUI was not sufficient 6 months later, because most boys had a dyssynergic pattern on urodynamics. These findings suggested that surgical indications for boys with a dyssynergic pattern should be limited.

Furthermore, the Kaplan-Meier analysis demonstrated that the follow-up period until daytime continence and dry nights was longer in the TUI+ than in the TUI- group. TUI did not worsen the urinary symptoms. Although there were no significant differences in baseline parameters between the groups (Table 1), there may be many intractable cases in the TUI+ group in the first place. Furthermore, the treatment effect of TUI may have been poor due to a high proportion of boys with a dyssynergic pattern. TUI may not have been effective for the boys in the present study, as they were not severe cases of PUV with decreased renal function, vesicoureteral reflux, or urinary tract infection. In general, boys with PUV achieve daytime and nighttime urinary continence significantly later than healthy controls. ${ }^{12}$ It is difficult to expect an immediate effect of TUI for boys with refractory DUI. We concluded that the effects of TUI for boys with refractory DUI due to PUV may sometimes be limited and care should be taken in deciding treatment.

This study had some limitations. First, our sample size was small. Therefore, more cases need to be enrolled for a more accurate evaluation of the TUI usefulness, and the surgical indication for boys with refractory DUI should be made clearer. Second, although there were no differences in the background factor groups, given the study retrospective design, the inclusion of TUI was dependent on the consent of the individual or family member, which could have introduced bias. If TUI had been performed on the TUI- group, its therapeutic effect would have remained unknown. Therefore, a prospective study is required for refractory patients with

B

Daytime Urinary Incontinence

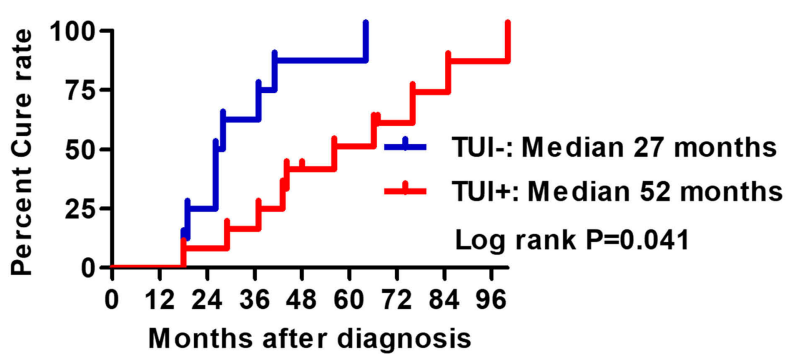

Nocturnal Enuresis

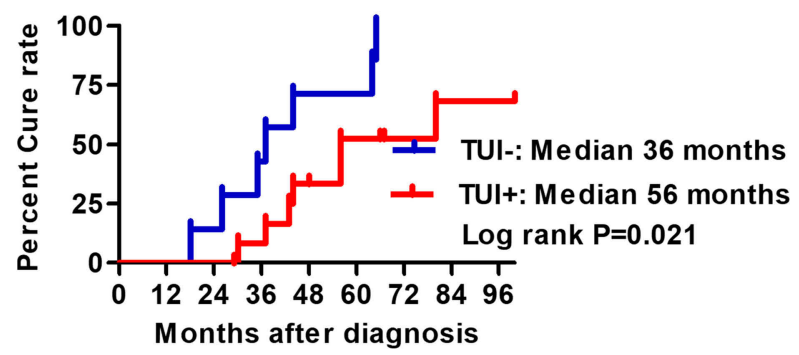

Figure 3 Kaplan-Meier curves of cure rate after initial treatment. (A) Overall, all and 10 (83\%) boys in the TUl- and the TUI+ group achieved daytime continence at a median of 27 and 52 months after initial treatment, respectively. (B) Overall, all and nine boys in the TUI- and the TUI+ group achieved dry nights at a median of 36 and 52 months after initial treatment, respectively. Abbreviation: TUI, transurethral incision. 
DUI. Third, the PUV diagnosis was subjectively assessed by two investigators. There is no reference standard based on the VCUG and endoscopy findings. ${ }^{13,14}$ Finally, postoperative VCUG alone was performed to confirm improvement in terms of obstruction. Only uroflowmetry was performed, but an urodynamic study was not performed after TUI. Therefore, it remains unclear whether there is still functional urethral obstruction by TUI.

\section{Conclusion}

This is the first report regarding the long-term outcomes of TUI for boys with refractory DUI. The efficacy of TUI in boys with refractory daytime incontinence might be very limited. It will be difficult to aggressively recommend TUI unless more positive data are published in the future. At least, surgical indications should be determined with sufficient explanation regarding the efficacy of TUI and patient consent before surgery.

\section{Author Contributions}

All authors contributed towards data analysis, drafting and critically revising the paper, gave final approval of the version to be published, and agreed to be accountable for all aspects of the work.

\section{Disclosure}

The authors report no conflicts of interest in this work.

\section{References}

1. Hagstroem S, Rittig N, Kamperis K, Mikkelsen MM, Ritig S, Djurhuus JC. Treatment outcome of day-time urinary incontinence in children. Scand J Urol Nephrol. 2008;42(6):528-533. doi:10.1080/ 00365590802098367

2. Chang SJ, van Laecke E, Bauer SB, et al. Treatment of daytime urinary incontinence: a standardization document from the International Children's Continence Society. Neurourol Urodyn. 2017;36(1):43-50. doi:10.1002/nau.22911

3. Sugimoto M, Kakehi Y, Yamashita M, Matsuki T, Inui M, Taketa S. Ten cases of congenital urethral stricture in childhood with enuresis. Int $J$ Urol. 2005;12(6):558-562. doi:10.1111/j.1442-2042.2005.010 90.x
4. Yohannes P, Hanna M. Current trends in the management of posterior urethral valves in the pediatric population. Urology. 2002;60(6):947953. doi:10.1016/S0090-4295(02)01621-7

5. Bomalaski MD, Anema JG, Coplen DE, Koo HP, Rozanski T, Bloom DA. Delayed presentation of posterior urethral valves: a not so benign condition. J Urol. 1999;162(6):2130-2132. doi:10.1016/ S0022-5347(05)68140-2

6. Nakamura S, Kawai S, Kubo T, Kihara T, Mori K, Nakai $H$. Transurethral incision of congenital obstructive lesions in the posterior urethra in boys and its effect on urinary incontinence and urodynamic study. BJU Int. 2011;107(8):1304-1311. doi:10.1111/j.1464-410X. 2010.09578.x

7. Hyuga $T$, Nakamura $S$, Kawai $S$, et al. The changes of urethral morphology recognized in voiding cystourethrography after endoscopic transurethral incision for posterior urethral valve in boys with intractable daytime urinary incontinence and nocturnal enuresis. World J Urol. 2017;35(10):1611-1616. doi:10.1007/s00345-0172018-4

8. Kihara T, Nakai H, Mori K, Sato R, Kitahara S, Yasuda K. Variety of congenital urethral lesions in boys with lower urinary tract symptoms and the results of endoscopic treatment. Int J Urol. 2008;15(3):235240. doi:10.1111/j.1442-2042.2007.01968.x

9. Nakai H, Hyuga T, Kawai S, Kubo T, Nakamura S. Aggressive diagnosis and treatment for posterior urethral valve as an etiology for vesicoureteral reflux or urge incontinence in children. Investig Clin Urol. 2017;58(Suppl 1):S46-S53. doi:10.4111/icu.2017.58.S1. S46

10. Zornoza M, Angulo JM, Parente A, Simal S, Burgos L, Ortiz R. Late diagnosis of posterior urethral valves. Actas Urol Esp. 2015;39 (10):646-650. doi:10.1016/j.acuro.2015.05.005

11. Özen MA, Taşdemir M, Gündoğdu G, Bilge I, Buyukunal C, Eroglu E. Does voiding cystourethrogram exclude posterior urethral valves in late presenting cases? Eur J Pediatr Surg. 2019;29(1):85-89. doi:10.1055/s-0038-1672146

12. Jalkanen J, Heikkilä J, Kyrklund K, Taskinen S. Controlled outcomes for achievement of urinary continence among boys treated for posterior urethral valves. J Urol. 2016;196(1):213-218. doi:10.1016/j.juro. 2016.02.2968

13. de Kort LMO, Uiterwaal CSPM, Beek EJA, Nievelstein RAJ, Klijn AJ, de Jong TPVM. Reliability of voiding cystourethrography to detect urethral obstruction in boys. Urology. 2004;63(5):967-971. doi:10.1016/j.urology.2003.11.047

14. de Jong TPVM, Radmayr C, Dik P, et al. Posterior urethral valves: search for a diagnostic reference standard. Urology. 2008;72 (5):1022-1025. doi:10.1016/j.urology.2008.04.037

15. Dewan PA, Keenan RJ, Morris LL, Le Quesne GW. Congenital urethral obstruction: Cobb's collar or prolapsed congenital obstructive posterior urethral membrane (COPUM). Br J Urol. 1994;73 (1):91-95. doi:10.1111/j.1464-410X.1994.tb07463.x

16. Cobb BG, Wolf JA Jr, Ansell JS. Congenital stricture of the proximal urethral bulb. J Urol. 1968;99(5):629-631. doi:10.1016/S0022-5347 (17)62761-7

Research and Reports in Urology

Dovepress

\section{Publish your work in this journal}

Research and Reports in Urology is an international, peer-reviewed, open access journal publishing original research, reports, editorials, reviews and commentaries on all aspects of adult and pediatric urology in the clinic and laboratory including the following topics: Pathology, pathophysiology of urological disease; Investigation and treatment of urological disease; Pharmacology of drugs used for the treatment of urological disease. The manuscript management system is completely online and includes a very quick and fair peer-review system, which is all easy to use. Visit http://www.dovepress.com/ testimonials.php to read real quotes from published authors. 